\title{
Top Starch Plating Method for the Efficient Cultivation of Unicellular Red Alga Cyanidioschyzon merolae
}

Tokiaki Takemura ${ }^{1,2}$, Yuki Kobayashi ${ }^{1}$, Sousuke Imamura ${ }^{1}$ and Kan Tanaka ${ }^{1, *}$

\author{
${ }^{1}$ Laboratory for Chemistry and Life Science, Institute of Innovative Research, Tokyo Institute of \\ Technology, Nagatsuta 4259-R1-29, Yokohama 226-8503, Japan; ${ }^{2}$ School of Life Science and \\ Technology, Tokyo Institute of Technology, Nagatsuta 4259-R1-29, Yokohama 226-8503, Japan \\ *For correspondence: kntanaka@res.titech.ac.jp
}

\begin{abstract}
[Abstract] The unicellular red alga Cyanidioschyzon merolae has been used as a model photosynthetic eukaryote for various basic and applied studies, and several of these molecular genetics techniques have been reported. However, there are still improvements to be made concerning the plating method. The conventional plating method often generates diffuse colonies and single colonies cannot be easily isolated. To overcome these problems, we established a novel plating method for C. merolae, making use of melted cornstarch as the use of top agar plating in bacterial genetics. This method improved the formation of defined colonies in at least 4 -fold higher efficiency than the conventional method, and made the handling procedure much easier than the previous method.
\end{abstract}

Keywords: Cyanidioschyzon merolae, Plating method, Single colony isolation, Top starch solution method, MA2

[Background] Cyanidioschyzon merolae 10D is a unicellular red alga that inhabits sulfate acid hot springs (Matsuzaki et al., 2004). It has a simple cellular structure, composed of a minimum set of organelles: one nucleus, one mitochondrion, and one plastid in a cell. C. merolae is used as a model organism to investigate the basic architecture of eukaryotes. Thus, many molecular genetics techniques have been developed using this organism, including antisense suppression, transient expression, gene disruption, and stable insertion into the genome (Minoda et al., 2004; Ohnuma et al., 2008; Imamura et al., 2009; Imamura et al., 2010; Zienkiewicz et al., 2017a; Zienkiewicz et al., 2017b; Zienkiewicz et al., 2018). The plating method for the selection of transformants is important for transformation experiments. However, C. merolae shows considerably low plating efficiencies (less than $0.5 \%$ ) on MA2 solid gellan gum plates. The direct spread of cells onto an MA2 solid gellan gum plate usually results in the death of the cells (Figure 1A). Hence, the plating method has been modified using the cornstarch embedding method which is commonly used for the cell-wall-less Chlamydomonas reinhardtii strain (Shimogawara et al., 1998). In the cornstarch embedding method, cells are grown on a starch bed prepared by spotting $20 \%$ slurry cornstarch on the MA2 solid gellan gum. Cells form colonies on the solid starch bed, but these are often diffused or blurred (Figure 1B).

To improve these points, we here devised a novel plating method using melted cornstarch (named in this protocol "top starch solution method"), similar to the top-agar plating method used in bacterial genetics. The $2 \%$ cornstarch in $\mathrm{dH}_{2} \mathrm{O}$ was melted at $98{ }^{\circ} \mathrm{C}$ for $10 \mathrm{~min}$. The melted cornstarch solution 
(= top starch solution) was mixed with an equal volume of the liquid MA2 medium containing C. merolae cells, and poured onto the surface of the MA2 solid gellan gum. Cells formed defined colonies using this plating method (Figure 1C). The plating efficiency of the top starch solution method was more than $2.0 \%$, while that of the conventional method was less than $0.5 \%$. In the conventional method, it was necessary to prepare many starch beds on solid plates prior to use, but the top starch solution method only requires the pouring of the melted starch-cell mixture onto the solid medium, making the plating procedure quick and easy. In this report, we describe the detailed procedure of the top starch solution method.

A Direct

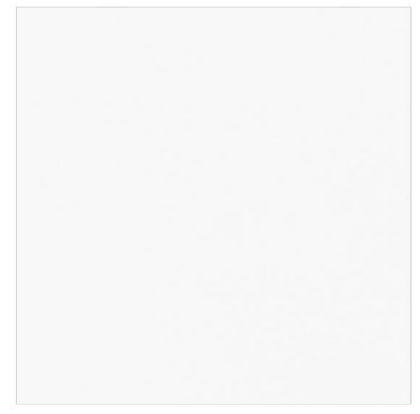

B Solid starch bed

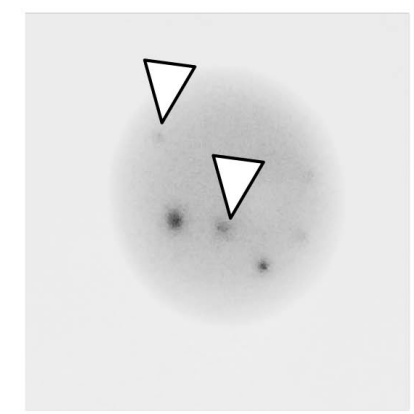

C Top starch solution

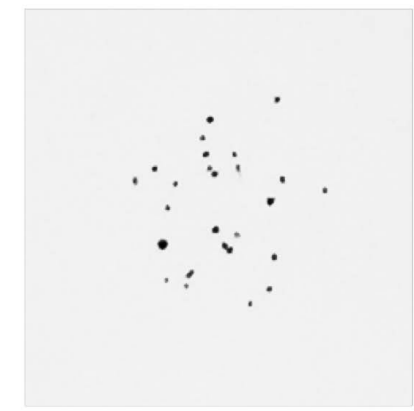

Figure 1. Effect of the top starch solution method on the colony formation in C. merolae. (AC) In each approach, plates with the spotted cells were incubated for two weeks at $40{ }^{\circ} \mathrm{C}$ under continuous white light. A. Five hundred cells were directly spotted onto an MA2 solid gellan gum plate, which resulted in no visible colony formation. B. Solid starch beds were made using $15 \mu \mathrm{l}$ of $20 \%$ slurry cornstarch in an MA2 liquid medium. Five hundred cells were spotted onto a solid cornstarch bed. Open triangles indicate diffused, blurred colonies. C. The $2 \%$ cornstarch in $\mathrm{dH}_{2} \mathrm{O}$ was melted at $98{ }^{\circ} \mathrm{C}$ for $10 \mathrm{~min}$ to make the top starch solution. The top starch solution was mixed with an equal volume of cells in MA2 medium. Fifteen microliter aliquots containing 500 cells were spotted onto the MA2 solid gellan gum plate.

\section{Materials and Reagents}

1. Pipette tips (NIPPON Genetics Co., Ltd., catalog numbers: FG-102, FG-301, FG-401)

2. Parafilm (LMS Co., Ltd., catalog number: PF, PM-996)

3. $1.5 \mathrm{ml}$ microtube (BM Equipment Co., Ltd., catalog number: NT-175)

4. $2.0 \mathrm{ml}$ microtube (WATSON Co., Ltd., catalog number: 132-620C)

5. $50 \mathrm{ml}$ centrifuge tube (Corning Incorporated., catalog number: 352196 )

6. AnaeroPouch (Mitsubishi Gas, catalog number: 2-3764-02)

7. AnaeroPack (Mitsubishi Gas, catalog number: 2-3765-01)

8. Sterilized plastic plate ( $\varnothing 90 \mathrm{~mm}$ ) (As One Corporation., catalog number: GD90-15)

9. Cyanidioschyzon merolae 10D [available as NIES-3377 from NIES collection, Tsukuba, Japan (http://mcc.nies.go.jp/index en.html)] 
10. Cornstarch (Kawamitsu-Bussan, catalog number: 4901486027016 )

11. Gellan gum (FUJIFILM Wako Pure Chemical Corporation, catalog number: 073-03071)

12. Uracil (Sigma-Aldrich, catalog number: U0750-5G)

13. 5-Fluoroorotic acid monohydrate (5-FOA) (FUJIFILM Wako Pure Chemical Corporation, catalog number: 003234)

14. Ethanol (FUJIFILM Wako Pure Chemical Corporation, catalog number: 055-00457)

15. $\left(\mathrm{NH}_{4}\right)_{2} \mathrm{SO}_{4}$ (FUJIFILM Wako Pure Chemical Corporation, catalog number: 019-03435)

16. $\mathrm{MgSO}_{4} \cdot 7 \mathrm{H}_{2} \mathrm{O}$ (FUJIFILM Wako Pure Chemical Corporation, catalog number: 138-00415)

17. $\mathrm{H}_{2} \mathrm{SO}_{4}$ (FUJIFILM Wako Pure Chemical Corporation, catalog number: 192-04696)

18. $\mathrm{H}_{3} \mathrm{BO}_{3}$ (FUJIFILM Wako Pure Chemical Corporation, catalog number: 021-02195)

19. $\mathrm{MnCl}_{2} \cdot 4 \mathrm{H}_{2} \mathrm{O}$ (FUJIFILM Wako Pure Chemical Corporation, catalog number: 133-00725)

20. $\mathrm{ZnCl}_{2}$ (FUJIFILM Wako Pure Chemical Corporation, catalog number: 268-01022)

21. $\mathrm{Na}_{2} \mathrm{MoO}_{4} \cdot 2 \mathrm{H}_{2} \mathrm{O}$ (FUJIFILM Wako Pure Chemical Corporation, catalog number: 198-02471)

22. $\mathrm{CoCl}_{2} \cdot 6 \mathrm{H}_{2} \mathrm{O}$ (FUJIFILM Wako Pure Chemical Corporation, catalog number: 038-03681)

23. $\mathrm{CuCl}_{2} \cdot 2 \mathrm{H}_{2} \mathrm{O}$ (FUJIFILM Wako Pure Chemical Corporation, catalog number: 039-04135)

24. $\mathrm{KH}_{2} \mathrm{PO}_{4}$ (FUJIFILM Wako Pure Chemical Corporation, catalog number: 169-04245)

25. $\mathrm{CaCl}_{2} \cdot 2 \mathrm{H}_{2} \mathrm{O}$ (FUJIFILM Wako Pure Chemical Corporation, catalog number: 038-19735)

26. $\mathrm{FeCl}_{3} \cdot 6 \mathrm{H}_{2} \mathrm{O}$ (FUJIFILM Wako Pure Chemical Corporation, catalog number: 090-02802)

27. $\mathrm{Na}_{2}$ EDTA (FUJIFILM Wako Pure Chemical Corporation, catalog number: $345-01865$ )

28. $20 \%$ slurry cornstarch stock solution (see Recipes)

29. MA2 medium (Kobayashi et al., 2010) (see Recipes)
a. MA2 solution I
b. A6 minor salts
c. MA2 solution II
d. MA2 solution III
e. MA2 solution IV

30. MA2 solid gellan gum plate (see Recipes)

\section{Equipment}

1. Pipettes (Gilson, Inc., catalog numbers: F123600, F123601, F123602)

2. Refrigerated centrifuge (Koki Holdings Co., Ltd., model: CF16RXII)

3. Microcentrifuge (TOMY Seiko Co., Ltd., model: MX150)

4. $500 \mathrm{ml}$ flask (IWAl, catalog number: 4442FK500)

5. Heat block (Chiyoda Science Co., Ltd., model: MiniT-100)

6. Bio incubator (TOMY Seiko Co., Ltd., model: CLE-303)

7. Clean bench (Panasonic Healthcare Co., Ltd., model: MCV-131BNF)

8. Vortex mixer (M \& S Instruments Inc., model: SI-0286)

9. Sterile filter ( $\varnothing 0.22 \mu \mathrm{m}$, Merck, catalog number: SLGV033RS) 


\section{Procedure}

1. Prepare the MA2 solid gellan gum plate and the $20 \%$ slurry cornstarch stock solution (see Recipes).

2. Mix $100 \mu \mathrm{l}$ of the cornstarch slurry stock solution and $900 \mu \mathrm{l}$ of sterile $\mathrm{dH}_{2} \mathrm{O}$ in a $2 \mathrm{ml}$ microtube.

3. Centrifuge the microtubes at $500 \times \mathrm{g}$ for $1 \mathrm{~min}$ at room temperature and discard the supernatant.

4. Add $900 \mu \mathrm{l}$ of sterile $\mathrm{dH}_{2} \mathrm{O}$ and mix vigorously.

5. Centrifuge again at $500 \times g$ for $1 \mathrm{~min}$ at room temperature and discard the supernatant.

6. Add $900 \mu \mathrm{l}$ of sterile $\mathrm{dH}_{2} \mathrm{O}$ and mix vigorously.

7. Incubate the microtube at $98{ }^{\circ} \mathrm{C}$ for $10 \mathrm{~min}$ but continue to mix thoroughly by inverting the tube every 2 min.

8. Cool down at room temperature for $10 \mathrm{~min}$ (= top starch solution).

Note: Steps 8-11 should be performed in a laminar flow cabinet.

9. Add $1 \mathrm{ml}$ of MA2 culture medium containing C. merolae cells (in case of wild type, 500 cells by microscopy observation) to the top starch solution and mix gently.

10. Pour the mixture onto the surface of the MA2 solid gellan gum plate and spread the mixture over the whole plate area by tilting the plate to spread the top starch solution uniformly.

11. Leave the plate open for 15-20 min to allow the top starch solution to solidify. After this step, the surface of the top starch is still wet, and the plate should be incubated with the top starch solution pointing upwards for the entire time.

12. Incubate the MA2 solid gellan gum plate at $40{ }^{\circ} \mathrm{C}$ under continuous white light (35-50 $\mu \mathrm{mol} \mathrm{m}^{-2} \mathrm{~s}^{-1}$ ) supplemented with $5 \% \mathrm{CO}_{2}$ in AnaeroPack with AnaeroPouch.

13. After 2-4 weeks, colonies of the transformed cells appear on the MA2 solid gellan gum plate.

\section{$\underline{\text { Recipes }}$}

1. $20 \%$ slurry cornstarch stock solution (Fujiwara and Ohnuma, 2018)

a. Add $10 \mathrm{~g}$ of cornstarch and $40 \mathrm{ml}$ of $\mathrm{dH}_{2} \mathrm{O}$ to the $50 \mathrm{ml}$ conical tube

b. Mix the tube well using a vortex mixer

c. Centrifuge the tube at $1,200 \times g$ for 5 min at $4{ }^{\circ} \mathrm{C}$

d. Discard the supernatant by decantation

e. Resuspend the pellet in $40 \mathrm{ml}$ of $100 \%$ of ethanol using a vortex mixer

f. Centrifuge the tube at $1,200 \times g$ for 5 min at $4{ }^{\circ} \mathrm{C}$

g. Discard the supernatant by decantation

h. Fill up to $50 \mathrm{ml}$ with $75 \%$ of ethanol

i. Store the tube at $4{ }^{\circ} \mathrm{C}$, wrapped using parafilm until use

2. MA2 medium

a. Mix $100 \mathrm{ml}$ of MA2 solution I, $10 \mathrm{ml}$ of MA2 solution II, $1 \mathrm{ml}$ of MA2 solution III and $885 \mathrm{ml}$ of $\mathrm{dH}_{2} \mathrm{O}$ in a glass bottle and sterilize by autoclaving 
b. Add $4 \mathrm{ml}$ of MA2 solution IV to the mixture in a laminar flow cabinet

\section{MA2 solution I}

\begin{tabular}{|l|l|l|l|}
\hline Components & Amount & Conc. & Final conc. in MA2 \\
\hline$\left(\mathrm{NH}_{4}\right)_{2} \mathrm{SO}_{4}$ & $52.9 \mathrm{~g}$ & $400 \mathrm{mM}$ & $40 \mathrm{mM}$ \\
\hline $\mathrm{MgSO}_{4} \cdot 7 \mathrm{H}_{2} \mathrm{O}$ & $9.9 \mathrm{~g}$ & $40 \mathrm{mM}$ & $4 \mathrm{mM}$ \\
\hline $\mathrm{H}_{2} \mathrm{SO}_{4}$ & $3 \mathrm{ml}$ & $0.3 \%(\mathrm{v} / \mathrm{v})$ & $0.03 \%(\mathrm{v} / \mathrm{v})$ \\
\hline $\mathrm{A} 6$ minor salts & $40 \mathrm{ml}$ & & \\
\hline $\mathrm{H}_{2} \mathrm{O}$ & Up to $1,000 \mathrm{ml}$ & & \\
\hline
\end{tabular}

\section{A6 minor salts}

\begin{tabular}{|l|l|l|l|}
\hline Components & Amount & Conc. & Final conc. in MA2 \\
\hline $\mathrm{H}_{3} \mathrm{BO}_{3}$ & $2.85 \mathrm{~g}$ & $46 \mathrm{mM}$ & $184 \mu \mathrm{M}$ \\
\hline $\mathrm{MnCl}_{2} \cdot 4 \mathrm{H}_{2} \mathrm{O}$ & $1.8 \mathrm{~g}$ & $9 \mathrm{mM}$ & $36.4 \mu \mathrm{M}$ \\
\hline $\mathrm{ZnCl} 2$ & $0.105 \mathrm{~g}$ & $0.77 \mathrm{mM}$ & $3.08 \mu \mathrm{M}$ \\
\hline $\mathrm{Na}_{2} \mathrm{MoO}_{4} \cdot 2 \mathrm{H}_{2} \mathrm{O}$ & $0.39 \mathrm{~g}$ & $1.6 \mathrm{mM}$ & $6.44 \mu \mathrm{M}$ \\
\hline $\mathrm{CoCl}_{2} \cdot 6 \mathrm{H}_{2} \mathrm{O}$ & $0.04 \mathrm{~g}$ & $0.17 \mathrm{mM}$ & $6.72 \mu \mathrm{M}$ \\
\hline $\mathrm{CuCl}_{2} \cdot 2 \mathrm{H}_{2} \mathrm{O}$ & $0.043 \mathrm{~g}$ & $0.25 \mathrm{mM}$ & $1.01 \mu \mathrm{M}$ \\
\hline $\mathrm{H}$ & Up to $1,000 \mathrm{ml}$ & & \\
\hline
\end{tabular}

\section{MA2 solution II}

\begin{tabular}{|l|l|l|l|}
\hline Components & Amount & Conc. & Final conc. in MA2 \\
\hline $\mathrm{KH}_{2} \mathrm{PO}_{4}$ & $10.9 \mathrm{~g}$ & $800 \mathrm{mM}$ & $8 \mathrm{mM}$ \\
\hline $\mathrm{H}_{2} \mathrm{O}$ & Up to $100 \mathrm{ml}$ & & \\
\hline
\end{tabular}

\section{MA2 solution III}

\begin{tabular}{|l|l|l|l|}
\hline Components & Amount & Conc. & Final conc. in MA2 \\
\hline $\mathrm{CaCl}_{2} \cdot 2 \mathrm{H}_{2} \mathrm{O}$ & $14.7 \mathrm{~g}$ & $1 \mathrm{M}$ & $1 \mathrm{mM}$ \\
\hline $\mathrm{H}_{2} \mathrm{O}$ & Up to $100 \mathrm{ml}$ & & \\
\hline
\end{tabular}

\section{MA2 solution IV}

\begin{tabular}{|l|l|l|l|}
\hline Components & Amount & Conc. & Final conc. in MA2 \\
\hline $\mathrm{FeCl}_{3} \cdot 6 \mathrm{H}_{2} \mathrm{O}$ & $0.68 \mathrm{~g}$ & $25 \mathrm{mM}$ & $0.1 \mathrm{mM}$ \\
\hline $\mathrm{Na}_{2} \mathrm{EDTA}$ & $0.74 \mathrm{~g}$ & $20 \mathrm{mM}$ & $0.075 \mathrm{mM}$ \\
\hline $\mathrm{H}_{2} \mathrm{SO}_{4}$ & 3 drops & & \\
\hline $\mathrm{H}_{2} \mathrm{O}$ & Up to $100 \mathrm{ml}$ & & \\
\hline
\end{tabular}

Note: This MA2 solution IV should be sterilized by filtration and stored at $4{ }^{\circ} \mathrm{C}$ in the dark. 
3. MA2 solid gellan gum plate (for making 9-10 plates)

a. Mix $30 \mathrm{ml}$ of MA2 solution I, $3 \mathrm{ml}$ of MA2 solution II, $300 \mu \mathrm{l}$ of MA2 solution III, and $70 \mathrm{ml}$ of $\mathrm{dH}_{2} \mathrm{O}$ in a $500 \mathrm{ml}$ flask. Mix $200 \mathrm{ml}$ of $\mathrm{dH}_{2} \mathrm{O}$ and $1.5 \mathrm{~g}$ of gellan gum in another $500 \mathrm{ml}$ flask. Sterilize these flasks by autoclaving, and subsequent plate preparation should be performed in a laminar flow cabinet

b. After autoclaving, mix both solutions and add $1.2 \mathrm{ml}$ of MA2 solution IV. In case of 5-FOA selection to isolate the URA deficient mutants (for example applying URA marker recycling system, Takemura et al., 2018; Takemura et al., 2019), add directly $150 \mathrm{mg}$ of uracil (final concentration: $0.5 \mathrm{mg} / \mathrm{ml}$ ) and $240 \mathrm{mg}$ of $5-\mathrm{FOA}$ (final concentration: $0.8 \mathrm{mg} / \mathrm{ml}$ ) in powder to the flask

c. Pour the mixed solution into the sterilized plastic plates

d. Dry the plates at room temperature for $15 \mathrm{~min}$

e. Store at $4{ }^{\circ} \mathrm{C}$ in the dark

\section{Acknowledgments}

This protocol was adapted from Takemura et al. (2018). The authors thank Y. Ide for technical assistance. This study was supported by MEXT/JSPS KAKENHI (Grant numbers: 17K07438 to S.I., 17K07439 to Y.K.) and by Advanced Low Carbon Technology Research and Development Program (ALCA) of Japan Science and Technology Agency (JST) to K.T.

\section{Competing interests}

No competing interests declared.

\section{$\underline{\text { References }}$}

1. Fujiwara, T. and Ohnuma, M. (2018). Procedures for transformation and their applications in Cyanidioschyzon merolae. In: Kuroiwa, T., Miyagishima, S.Y., Matsunaga, S., Sato, N., Nozaki, H., Tanaka, K. and Misumi, O. (Eds.). Cyanidioschyzon merolae. Singapore, Springer Singapore: 87-103.

2. Imamura, S., Kanesaki, Y., Ohnuma, M., Inouye, T., Sekine, Y., Fujiwara, T., Kuroiwa, T. and Tanaka, K. (2009). R2R3-type MYB transcription factor, CmMYB1, is a central nitrogen assimilation regulator in Cyanidioschyzon merolae. Proc Natl Acad Sci U S A 106(30): 1254812553.

3. Imamura, S., Terashita, M., Ohnuma, M., Maruyama, S., Minoda, A., Weber, A. P., Inouye, T., Sekine, Y., Fujita, Y., Omata, T. and Tanaka, K. (2010). Nitrate assimilatory genes and their transcriptional regulation in a unicellular red alga Cyanidioschyzon merolae: genetic evidence for nitrite reduction by a sulfite reductase-like enzyme. Plant Cell Physiol 51(5): 707-717. 
4. Kobayashi, Y., Ohnuma, M., Kuroiwa, T., Tanaka, K., and Hanaoka, M. (2010). The basics of cultivation and molecular genetic analysis of the unicellular red alga Cyanidioschyzon merolae. Endocytobiosis Cell Res 20: 53-61.

5. Matsuzaki, M., Misumi, O., Shin-I, T., Maruyama, S., Takahara, M., Miyagishima, S. Y., Mori, T., Nishida, K., Yagisawa, F., Nishida, K., et al. (2004). Genome sequence of the ultrasmall unicellular red alga Cyanidioschyzon merolae 10D. Nature 428(6983): 653-657.

6. Minoda, A., Sakagami, R., Yagisawa, F., Kuroiwa, T. and Tanaka, K. (2004). Improvement of culture conditions and evidence for nuclear transformation by homologous recombination in a red alga, Cyanidioschyzon merolae 10D. Plant Cell Physiol 45(6): 667-671.

7. Ohnuma, M., Yokoyama, T., Inouye, T., Sekine, Y. and Tanaka, K. (2008). Polyethylene glycol (PEG)-mediated transient gene expression in a red alga, Cyanidioschyzon merolae 10D. Plant Cell Physiol 49(1): 117-120.

8. Shimogawara, K., Fujiwara, S., Grossman, A. and Usuda, H. (1998). High-efficiency transformation of Chlamydomonas reinhardtii by electroporation. Genetics 148(4): 1821-1828.

9. Takemura, T., Imamura, S., Kobayashi, Y. and Tanaka, K. (2018). Construction of a selectable marker recycling system and the use in epitope tagging of multiple nuclear genes in the unicellular red alga Cyanidioschyzon merolae. Plant Cell Physiol 59(11): 2308-2316.

10. Takemura, T., Imamura, S., Kobayashi, Y. and Tanaka, K. (2019). Preparation of introducing DNA fragment for multiple modification of chromosomal loci in the unicellular red alga Cyanidioschyzon merolae. Bio-protocol (In-review).

11. Zienkiewicz, M., Krupnik, T., Drożak, A., Golke, A. and Romanowska, E. (2017a). Chloramphenicol acetyltransferase-a new selectable marker in stable nuclear transformation of the red alga Cyanidioschyzon merolae. Protoplasma 254(1): 587-596.

12. Zienkiewicz, M., Krupnik, T., Drożak, A., Golke, A. and Romanowska, E. (2017b). Transformation of the Cyanidioschyzon merolae chloroplast genome: prospects for understanding chloroplast function in extreme environments. Plant Mol Biol 93(1-2): 171-183.

13. Zienkiewicz, M., Krupnik, T., Drożak, A., Wasilewska, W., Golke, A. and Romanowska, E. (2018). Deletion of $p s b Q^{\prime}$ gene in Cyanidioschyzon merolae reveals the function of extrinsic PsbQ' in PSII. Plant Mol Biol 96(1-2): 135-149. 